\title{
Relative Prognostic Significance of Vasospasm Following Subarachnoid Hemorrhage
}

\author{
BRYCE WEIR, CHARLES ROTHBERG, MICHAEL GRACE AND FAYE DAVIS
}

SUMMARY: $A$ retrospective analysis of 274 patients with intracranial aneurysms, diagnosed either angiographically or at autopsy between 1968 and 1973 at the University of Alberta, was carried out. One hundred and forty-six patients had intracranial clipping of the aneurysm. Clinical and radiologic data were abstracted from the chart and the angiographic studies. Probability of survival curves were constructed. Associations between various clinical factors and survival at two

RÉSUMÉ: Une analyse rétrospective de 274 patients avec anévrisme intracrânien, diagnostiqués à l'Université de l'Alberta soit par angiographie ou par autopsie entre 1968 et 1973, est présentée. Cent quarante-six patients furent traités par "clip" intracrânien sur l'anévrisme. Les données cliniques et radiologiques ont été obtenues du dossier et des études angiographiques. La probabilité des courbes de survie fut établie, démontrant par le fait même une association entre divers facteurs cliniques et de survie à deux mois. Les facteurs pronostiques les months were demonstrated. The most important prognostic factors were the clinical grade at angiography or surgery, followed by the presence of preoperative spasm, hematoma or focal edema, elevated blood pressure on admission, time interval from hemorrhage to surgery and age. The data lends some support to the policy of operating on patients in good neurological condition, even if their pre-operative angiogram shows spasm.

plus importants étaient l'état clinique lors de l'angiographie ou de la chirurgie, ainsi que la présence de spasme préopératoire, d'hématome ou d'oédème focalisé, une tension artérielle élevée à l'admission et enfin l'intervalle de temps entre l'hémorragie et la chirurgie ainsi que l'âge. Il est conclu que ces observations favorisent l'opération de patients en bonne condition neurologique, même si l'angiogramme préopératoire montre la présence de spasme.
From the Division of Neurosurgery, University of Alberta, Dr. W. W. Cross Institute, Edmonton, Canada.

Presented in part at the "9th Canadian Congress of Neurological Sciences", Saskatoon, June, 1974.

Reprint requests to $\mathrm{Dr}$. B. K. A. Weir, 11560 University Avenue, Edmonton, Canada T6G 122.

\section{INTRODUCTION}

It is more than twenty years since Ecker and Riemenschneider (1951) demonstrated arteriographic spasm of the intracranial arteries following rupture of saccular, intracranial aneurysms. There was some initial reluctance to accept this phenomenon as a significant feature following subarachnoid hemorrhage, but numerous studies subsequently demonstrated its importance. Through the years the pendulum of enthusiasm for vasospasm swung dramatically to the point where it was considered to be ". . . . the pivotal factor determining recovery or death of patients." (Stornelli and French, 1964) and ". .. the main cause of postoperative morbidity and mortality in patients with ruptured intracranial aneurysms." (Allcock and Drake, 1965).

More recent clinical studies have demonstrated what appears to be the overwhelming significance of the patient's neurological status, following subarachnoid hemorrhage, as the principle determinant of subsequent morbidity and mortality. Alvord et al (1972), depending principally upon the data of Pakarinen (1967), MacKissock (1965) and their own, devised a method of estimating prognosis following rupture of an aneurysm. They considered the two significant variables were the clinical grade of the patient and the time from rupture.

The early studies on spasm did not adequately consider time span and clinical grade interactions and most clinical studies did not carry out a simultaneous analysis of vasospasm on the angiograms.

\section{METHOD}

We have carried out a retrospective analysis of 274 patients with 
TABLE 1

Percentage of surviving patients, graded clinically at the time of first angiogram and the time (in days) from SAH (subarachnoid hemorrhage) to the first angiogram.

\begin{tabular}{ccccccc}
$\begin{array}{c}\text { Grade at } \\
\text { First } \\
\text { Angiogram }\end{array}$ & \multicolumn{7}{c}{ DAYS } \\
\cline { 2 - 7 } 1 & $0-1$ & $2-3$ & $4-7$ & $8-21$ & $22+$ & Total \\
\cline { 2 - 7 } 1 & $100 \%$ & $80 \%$ & $88 \%$ & $100 \%$ & $100 \%$ & $94 \%$ \\
& $(22 / 22)$ & $(12 / 15)$ & $(7 / 8)$ & $(18 / 18)$ & $(4 / 4)$ & $(63 / 67)$ \\
2 & $88 \%$ & $71 \%$ & $89 \%$ & $75 \%$ & $83 \%$ & $82 \%$ \\
& $(7 / 8)$ & $(10 / 14)$ & $(16 / 18)$ & $(3 / 4)$ & $(5 / 6)$ & $(41 / 50)$ \\
3 & $80 \%$ & $68 \%$ & $40 \%$ & $82 \%$ & $100 \%$ & $70 \%$ \\
& $(12 / 15)$ & $(13 / 19)$ & $(4 / 10)$ & $(9 / 11)$ & $(1 / 1)$ & $(39 / 56)$ \\
4 & $27 \%$ & $20 \%$ & $50 \%$ & $33 \%$ & $0 \%$ & $26 \%$ \\
& $(4 / 15)$ & $(3 / 15)$ & $(1 / 2)$ & $(2 / 6)$ & $(0 / 1)$ & $(10 / 39)$ \\
5 & $5 \%$ & $0 \%$ & $0 \%$ & $0 \%$ & $0 \%$ & $3 \%$ \\
& $(1 / 19)$ & $(0 / 6)$ & $(0 / 2)$ & $(0 / 2)$ & $(0 / 1)$ & $(1 / 30)$ \\
& $58 \%$ & $55 \%$ & $70 \%$ & $78 \%$ & $77 \%$ & $64 \%$ \\
TOTAL & $(46 / 79)$ & $(38 / 69)$ & $(28 / 40)$ & $(32 / 41)$ & $(10 / 13)$ & $(154 / 242)$
\end{tabular}

intracranial aneurysms, diagnosed either angiographically or at ąutopsy, in which the above mentioned factors were studied concurrently. These patients were diagnosed between 1968 and 1973 in the two largest teaching hospitals at the University of Alberta.

Individual patient data was abstracted from the chart, coded, and mounted on magnetic tape. Each set of angiograms was also examined and a subjective judgment made as to whether or not spasm was present. As there was sometimes more than one angiogram on each patient, this data was initially studied separately and later merged with the core of clinical data. Analysis was carried out on an IBM $360 / 67$ computer.

\section{RESULTS}

Two hundred and seventy-four patients had aneurysms of which 251 were ruptured. Of these, 146 were operated upon by intracranial clipping and 38 had different operative procedures. Ninety patients had no surgery.

The patients in our series were compared to the patients in the original cooperative study (Sahs et al., 1969) with reference to age, sex and location of aneurysm. Our series shows no major differences from the largest aneurysm study to date.

The percentage of patients alive, categorized into clinical grading
(Nishioka classification, Sahs et al., 1969) at first angiogram and the time interval from SAH (subarachnoid hemorrhage) to the first angiogram is given in Table 1.

Table 2 gives calculated and observed survival probability values. The calculated rate is the probability of a patient surviving two years, given they are alive on the day after SAH as specified by each column. This was calculated using the graphical method discussed by Alvord et al (1972). The observed rate is the actual percentage of cases we observed to be alive after 2 years given they were alive at the day specified in the column. Thus, for clinical grade III patients who have survived for 21 days, the observed percentage of two year survivors was 83 and the calculated percentage, using Alvord Method was 86 .

We thought it was of interest to consider the influence of the individual surgeon on outcome (Table 3 ). None of the differences between surgeons were statistically significant. Microsurgical techniques were introduced late in this series. It was our impression that this improved results for the group as a whole, but insufficient numbers were available for anlaysis.

Tests of association were used to relate pre and post operative spasm by patient in relation to survival at two months (Tables 4, 5).

The measurements of intracranial arteries and the development of "spasm index" were based on the normal measurements given by Gabrielson and Greitz (1970), shown in Figure 1. The frequency distribution of spasm index ratios for angiograms

\section{TABLE 2}

Probability of 2-year survival after first major subarachnoid hemorrhage as functions Calculated

Observed of duration of past survival and clinical grading.

Clinical Grade

1

2

3

4

5

All grades

DAYS AFTER SAH

\section{1}

3

4

All grades with surgery

All grades without surgery

\begin{tabular}{|c|c|c|c|c|c|c|}
\hline \multicolumn{7}{|c|}{ DAYS AFTER SAH } \\
\hline 1 & 3 & 7 & 14 & 21 & 30 & 60 \\
\hline 87 & 90 & 92 & 94 & 95 & 96 & 98 \\
\hline 21 & 21 & 21 & 27 & 97 & 27 & $\underline{98}$ \\
\hline$\overline{64}$ & 71 & 76 & 80 & $\overline{82}$ & 84 & 88 \\
\hline$\underline{72}$ & 72 & 75 & 75 & 78 & $\mathbf{8 4}$ & $\underline{88}$ \\
\hline 61 & $\overline{69}$ & $\overline{76}$ & $\overline{82}$ & 86 & 90 & 97 \\
\hline$\underline{68}$ & $\underline{69}$ & $\underline{72}$ & 79 & $\underline{\mathbf{8 3}}$ & $\underline{93}$ & 97 \\
\hline 21 & 32 & $\overline{44}$ & $\overline{57}$ & $\overline{67}$ & $\overline{77}$ & $\overline{100}$ \\
\hline 26 & 30 & 38 & 63 & 71 & 83 & 100 \\
\hline 2 & 7 & 14 & 27 & 39 & $\overline{53}$ & 100 \\
\hline 4 & $\underline{6}$ & 8 & $\underline{25}$ & $\underline{50}$ & $\underline{50}$ & 100 \\
\hline 56 & 65 & 72 & 79 & 83 & 87 & 95 \\
\hline 61 & 66 & 71 & 82 & 85 & 91 & 95 \\
\hline 68 & 74 & 80 & 84 & 87 & 90 & 95 \\
\hline 72 & 73 & $\underline{77}$ & 85 & 88 & 91 & 95 \\
\hline 29 & 41 & $\overline{53}$ & 65 & $\overline{73}$ & $\overline{81}$ & 100 \\
\hline$\underline{33}$ & 42 & 50 & 67 & 76 & 92 & 100 \\
\hline
\end{tabular}


TABLE 3

Influence of Individual Neurosurgeons

\begin{tabular}{lccccc}
\hline & 1 & 2 & 3 & 4 & 5 \\
\hline Total number cases & 80 & 25 & 35 & 38 & 66 \\
Overall mortality (dead $<2$ months) & $30 \%$ & $40 \%$ & $31 \%$ & $32 \%$ & $35 \%$ \\
\hline Cases clipped & 46 & 16 & 23 & 21 & 36 \\
Clipping mortality (dead $<2$ months) & $15 \%$ & $31 \%$ & $22 \%$ & $19 \%$ & $14 \%$ \\
\hline
\end{tabular}

Average grade at clipping:

\begin{tabular}{llllll} 
All & 2.1 & 2.3 & 2.2 & 2.3 & 2.0 \\
Dead & 2.9 & 3.0 & 2.8 & 3.2 & 2.7 \\
Alive & 1.9 & 1.9 & 2.0 & 2.1 & 1.9 \\
\hline
\end{tabular}

Average time (days) SAH to clipping:

\begin{tabular}{lccccc} 
All & 11 & 25 & 9 & 7 & 11 \\
Dead & 7 & 5 & 9 & 5 & 6 \\
Alive & 13 & 34 & 9 & 8 & 12 \\
\hline Cases without SAH & $5 \%$ & $4 \%$ & $11 \%$ & $7 \%$ & $15 \%$ \\
\hline Average time (days) to last follow-up & 307 & 75 & 211 & 300 & 316
\end{tabular}

TABLE 4

Survival by Pre-Operative Presence or Absence of Spasm

\begin{tabular}{cc}
234 Patients & \\
\hline $\begin{array}{c}\text { Pre-Op } \\
\text { Spasm }\end{array}$ & $\begin{array}{c}\text { No Pre-Op } \\
\text { Spasm }\end{array}$
\end{tabular}

$\begin{array}{lcc}\text { ALIVE } & & \\ 2 \mathrm{MO} & 40 & 110 \\ & 50 \% & 71 \%\end{array}$

DEAD

$\begin{array}{ccc}2 \text { MO } & 40 & 44 \\ 50 \% & 29 \% \\ & & \\ \text { p. }<.01 & \end{array}$

TABLE 5

Survival by Post-Operative Presence or Absence of Spasm

133 Patients

\begin{tabular}{lcc}
\hline & $\begin{array}{c}\text { Post-Op } \\
\text { Spasm }\end{array}$ & $\begin{array}{c}\text { No Post-Op } \\
\text { Spasm }\end{array}$ \\
\hline ALIVE & & \\
2 MO & 75 & 37 \\
& $78 \%$ & $100 \%$
\end{tabular}

DEAD

$\begin{array}{ccc}2 \text { MO } & 21 & 0 \\ 22 \% & 0 \% \\ & \text { p. }<.01\end{array}$

on patients who were either dead or alive at two months is given in Figure 2. Those patients who subsequently died, had a significantly diminished spasm index and the distribution curve was skewed in the direction of a diminished index. This demonstrates that the patients who died had a significantly reduced diameter of all their intracranial arteries compared to a fixed extracra-
Rupture During Surgery nial arterial point. The time-duration curve of spasm in pre-operative angiography is shown in Figure 3. An investigation of the pattern of spasm index distribution showed no apparent difference between the lower and higher grades.

Tests of association relating all clinical factors to status (alive or dead) at two months post SAH and the resulting level of significance are given in Table 6.

A multiple regression analysis of the seven major clinical variables affecting surgical outcome (grade at angiography, pre-operative spasm, age, days to surgery, grade at surgery, presence of a mass lesion on angiography, and blood pressure on admission) were carried out to assess their relative importance (Table 7). Grade at angiography made the largest contribution to the explanation of variance between being alive or dead at two months post-SAH, followed in order by pre-operative spasm, blood pressure, age, mass lesion, days to surgery, and grade at surgery. In the variance column the grade at surgery had a small additional impact due to its strong correlation with grade at angiography. As the fraction of the variance of surgical outcome attributable to the clinical variables

\section{TABLE 6}

Associations between "Alive or Dead at 2 months Post SAH" and other Factors

Level of Significance
Factor

Grade at Angiography

$\mathrm{p}<.01$

Time from SAH to Surgery

Grade at Surgery

Hematoma or Edema

Blood Pressure on Admission

Spasm - pre-op or post-op

Age (in decades)

$p<.05$

Anesthetic Time

Lowest Blood Pressure at Surgery

Not Significant

Lowest Temperature at Surgery

Time of Temporary Clips

Number of Units Blood at Surgery

Use of Osmotic Agent at Surgery

Size of Aneurysm 


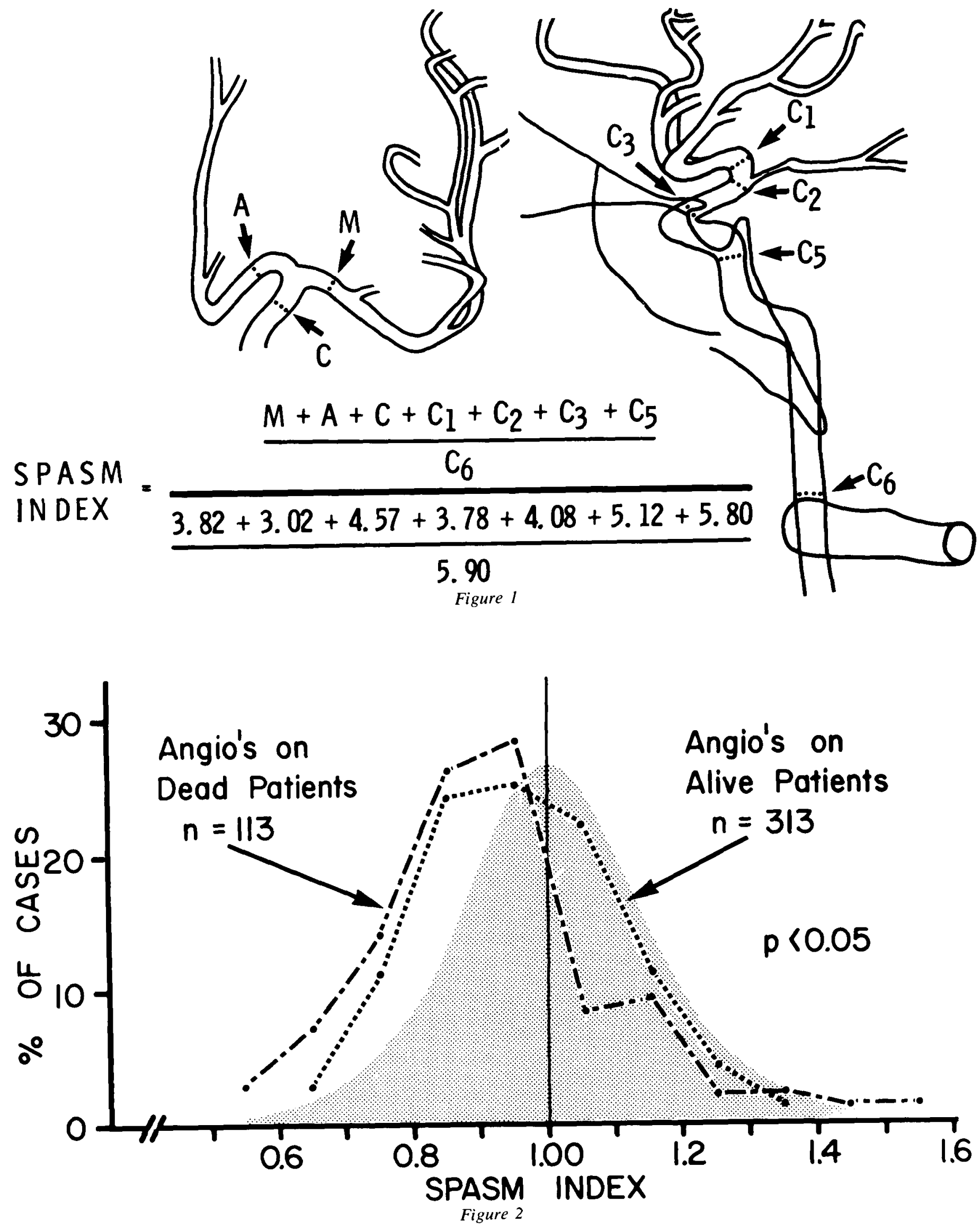


TABLE 7

Multiple regression analysis relating major clinical variables to "Alive or Dead at 2 months Post SAH"'(135 cases)

\begin{tabular}{lcc} 
Variable & $\begin{array}{c}\text { Explained } \\
\text { Variance (\%) }\end{array}$ & $\begin{array}{c}\text { Simple Correlation } \\
\text { (Absolute Value) }\end{array}$ \\
\hline Grade at Angiography & 12.7 & 0.36 \\
Pre-operative spasm & 6.6 & 0.28 \\
Blood pressure & 3.0 & 0.20 \\
Age & 2.0 & 0.06 \\
Hematoma or Focal Edema & .6 & 0.23 \\
Days to Surgery Post SAH & .5 & 0.10 \\
Grade at Surgery & .1 & 0.34 \\
TOTAL & 25.4 &
\end{tabular}

measured was only $25.4 \%$, it must be assumed that the remainder of the variation was due to variables not included in the regression. Table 7 also gives the relative contributions of each variable considered independently of the others and its simple correlation with the dependent variable (alive or dead at two months post-SAH). The greater the numerical value, the greater the importance of the factor in determining the outcome. The independent variables exhibiting the highest simple correlations with the dependent variable of surgical outcome were grade at angiography and grade at surgery. More modest correlations existed with pre-operative spasm, presence of a mass lesion and blood pressure. The time interval to surgery postSAH and age showed only a limited relationship with the dependent variable.

\section{DISCUSSION}

Our results are in accord with the cooperative study (Sahs et al., 1969) which found the chances of surviving six months were improved in those patients having good clinical grades, an increased time interval between subarachnoid hemorrhage and angiography or surgery and a younger age. The significance of site of aneurysm in determining the prognosis appeared to have some importance in the cooperative study, but in our data the contribution to post-operative status was marginal.

The most recent group study (Graf and Nibbelink, 1974) found the incidence of spasm to be unrelated to sex, age, site of aneurysm or blood pressure but it was increased in patients having a significantly deteriorated neurological grade. Despite this latter association the authors noted "... many severe deficits may be present without vasospasm or vice versa."

From our data, it appears that the relationship of arterial spasm to a poor prognosis is significant but of less significance than grade at initial angiography or surgery. This overriding significance of grade in comparison to the presence of spasm implies that operation should probably not be delayed in Grade I or II patients just because they have spasm. It should be considered that the principal rationale of surgery, aside from the evacuation of an expanding space occupying lesion (hematoma or edema), is to prevent a rebleed. The cooperative study (Sahs et al., 1969), indicated that the probability of a rebleed was $13 \%$ in the first seven days from $\mathrm{SAH}$, $25 \%$ in the first fourteen days and $31 \%$ in the first 21 days. The mortality from rebleed is in the area of $46 \%$ for internal carotid aneurysms, $42 \%$ for anterior cerebral and $41 \%$ for middle cerebral aneurysms. A policy of routinely waiting three weeks to operate appears likely to result in a 10 to $15 \%$ mortality during the waiting interval. In Pakarinen's data (1967), the mortal-

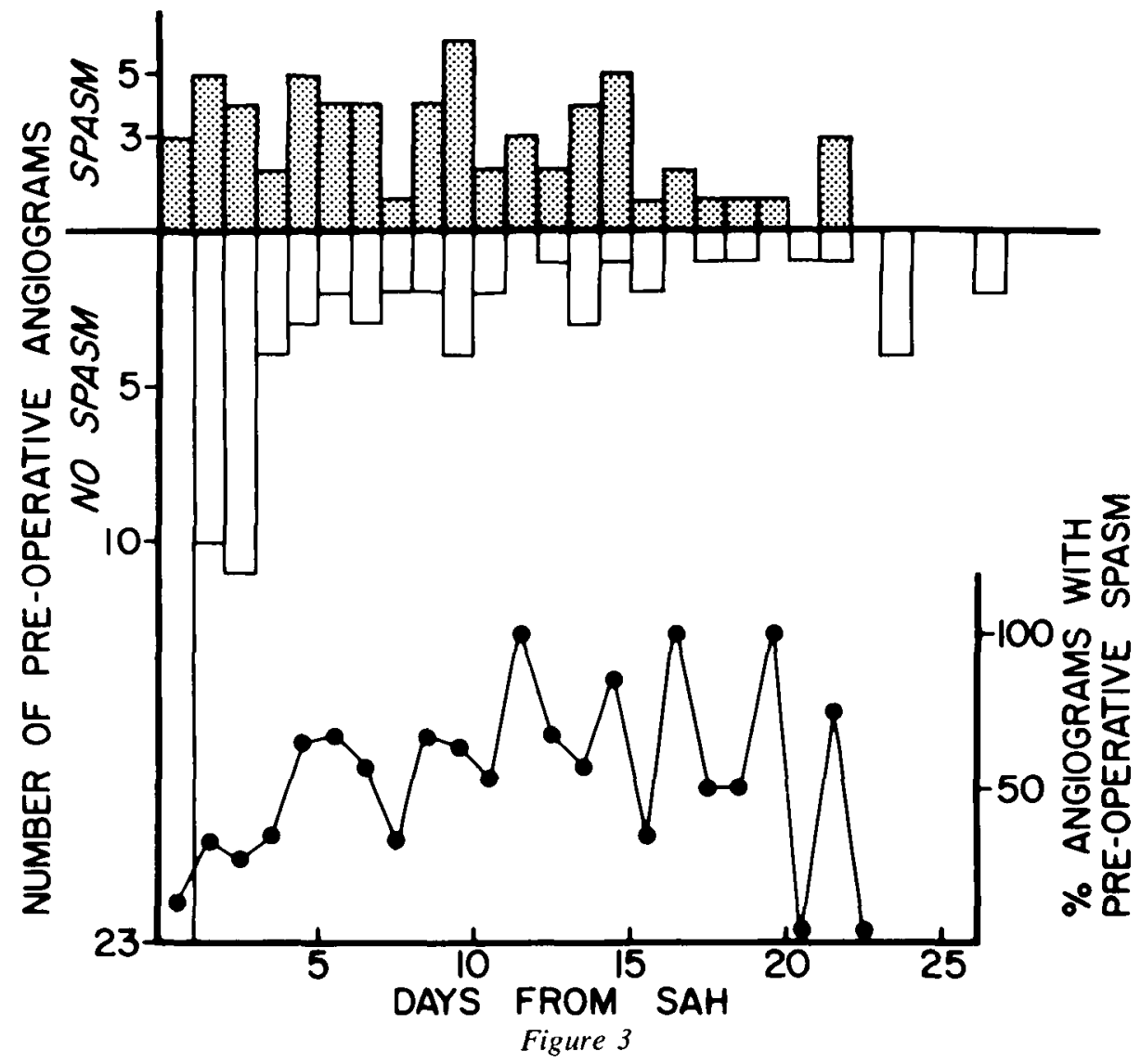


ity from recurrent hemorrhage in the first three weeks was $20 \%$.

Patients who have a progressive degree of spasm visualized angiographically, occasionally show a concurrent improvement in their clinical grades. The basis for this lies in the fact that neurological status of the brain depends on more variables than the diameter of the large conducting arteries. Virtually every series published indicates that spasm has a deleterious effect on outcome - the effect, however, would have to be greater than the loss from recurrent hemorrhage in order to justify a policy of waiting the three weeks that is required for the risk of spasm to disappear.

If anti-fibrinolysis therapy or other medical means of preventing rebleed can be found this would increase the desirability of waiting until angiographic spasm had disappeared. Until then, our data substantiates the clinical practice of the Zurich school (Krayenbuhl et al., 1972) in operating on patients in good neurological condition, even if their pre-operative angiograms show spasm. While some patients may suffer as a result of this policy being uniformly adopted, in the long run, it seems that mortality and morbidity would be reduced.

A definitive response to the question "will early operation on patients in good neurological condition but with spasm, reduce postoperative morbidity and mortality?", cannot be made on retrospective data. This study suggests, however, that the answer may well be in the affirmative at the present time.

\section{REFERENCES}

ALLCOCK, J. M., and DRAKE, C. G. (1965): Ruptured intracranial aneurysms the role of arterial spasm. Journal of Neurosurgery, 22: 21-29.

ALVORD, E. C., LOESER, J. D., BAILEY, W. L., and COPASS, M. K. (1972): Subarachnoid hemorrhage due to ruptured aneurysms. A simple method of estimating prognosis. Archives of Neurology, 27: 273-284.

ECKER, A., RIEMENSCHNEIDER, P. A. (1951): Arteriographic demonstration of spasm of the intracranial arteries with special reference to saccular intracranial aneurysm. Journal of Neurosurgery, 8: 660-667.

GABRIELSON, T. O., and GREITZ, T. (1970): Normal size of the internal carotid, middle cerebral and anterior cerebral arteries. Acta Radiologica 10: 1-10.

GRAF, C. J. and NIBBELINK, D. W. (1974): Cooperative study of intracranial aneurysms and subarachnoid hemorrhage. Report on a randomized treatment study. III. Intracranial surgery. Stroke 5: 559-601.

KRAYENBUHL, H. A., YASARGIL, M. G., FLAMM, E. S., TEW, J. M. (1972): Microsurgical treatment of intracranial saccular aneurysms. Journal of Neurosurgery, 37: 678-686.

McKISSOCK, W., RICHARDSON, A., WALSH, L. (1965): Anterior communicating aneurysms: A trial of conservative and surgical treatment. Lancet, 1: 873-876.

PAKARINEN, S. (1967): Incidence, aetiology and prognosis of primary subarachnoid hemorrhage. Acta Neurologica Scandinavia, 43 (suppl. 29): 1-127.

SAHS, A. L., PERRET, G. E., LOCKSLEY, H. B., and NISHIOKA, H. (1969): Intracranial aneurysms and subarachnoid hemorrhage. A cooperative study. Philadelphia and London. J. B. Lippincott Company, $296 \mathrm{pp}$.

STORNELLI, S. A., and FRENCH, J. D. (1964): Subarachnoid hemorrhage-factors in prognosis and management. Journal of Neurosurgery, 21: 769-780. 